\title{
Recent degradation process of a tropical secondary forest in West Sumatra
}

\author{
Elias Thiam ${ }^{1}$ and Tsuyoshi Yoneda ${ }^{1 *}$ \\ 'Faculty of Agriculture, Kagoshima University, Kagoshima, 890-0065, Japan. \\ *Corresponding author: yoneda@agri.kagoshima-u.ac.jp
}

\begin{abstract}
Long-term observations were conducted over the last 16 years to assess the degradation processes within a secondary forest in an equatorial region in Sumatra Island. Two belt transects representing $5.6 \mathrm{~km} \times 10 \mathrm{~m}$ in total and two permanent plots of 1.8 ha were used. A secondary forest located below $300 \mathrm{~m}$ in altitude was largely lost over the last 8 years, and this deforestation, which was largely caused by clearing for fields and logging for timber by the local people, expanded to a forest at $500 \mathrm{~m}$ in altitude, $3 \mathrm{~km}$ from the nearest village. Based on the mortality of the trees with the examined parameters (density and basal area) and distance from the village, we concluded that a secondary forest below $500 \mathrm{~m}$ in altitude will be greatly retrogressed within the next 16 years, and the original floristic features of a hill forest below $1050 \mathrm{~m}$ in altitude will disapper within next 32 years.
\end{abstract}

Key words: human impacts, mortality, temporal changes, topography, tropical secondary forest

\section{INTRODUCTION}

Different types of land use can accelerate altitudinal and horizontal forest degradation (Lambin et al. 2001, Kobayashi 2004). This social trend, which is linked to forest dynamics, is a major global issue because it causes significant land cover changes in tropical rain forests (Vitousek et al. 1997, Nishimura et al. 2006).

Indonesia has the third largest forested area in the world (FWI/GFW. 2002). It is also ranked $3^{\text {rd }}$ among the World' 17 mega-diverse countries (ASEAN 2009). However, the biodiversity of tropical forest ecosystems is declining in many areas for a variety of reasons. For example, forest changes related to physical factors such as drought effects (e.g., 1997-1998) and natural disasters, as well as economic issues that set short-term values on unsustainable ecosystem services (William 1999, Yoneda et al. 2006, Vihervaara et al. 2010) resulted in deforestation. Sumatra lost forest area at a rate of $55 \mathrm{~km}^{2}$ per year during 1985-2007, and only 30\% of the forested land area remains (Laumonier et al. 2010). The oil palm and paper industries are major drivers of deforestation in this area. In West Sumatra, secondary forests are facing high rates of disturbances due to the rapid decrease of natural resource availability (Sheil and Burslem 2003). Yoneda et al. (2006) observed a continuous change in species composition, biomass, and productivity in this region. The dynamics of secondary forests based on biomass studies are well documented, whereas few studies focus specifically on temporal and spatial scales based on long-term observations related to human impacts.

Some disturbance in a tropical secondary forest can be useful for forest productivity, biodiversity, succession, and advanced regeneration because it allows for habitat sharing among shade intolerant and fast-growing species (Yamamoto 1992, Everham and Brokaw 1996, Whitmore 1998). This seemingly inevitable change is strongly coupled with the social systems (Folke et al. 2002, Kimmins 2004, Otsuka 2009). Repeated disturbances induce changes in the process of natural succession and biomass production. Human interference in forested areas must be effectively managed under regulations that consider stand density (Julian 1992, Top et al. 2008). The 
aim of this study was to assess the recent use of a secondary forest and retrogressive process with stem density and basal area as major parameters.

It is important to understand the influences of spatial and temporal patterns on biotic processes by considering demographic parameters such as mortality traits and recruitment processes. The purpose of this study was to describe landscape patterns and recent stand dynamics by assessing the distance of a forest from the human settlements. Ecological dynamics under recent management by the Minangkabau community were evaluated. This area has been recognized as an example of sustainable land use in the tropics (Yoneda 2000). Thanks to stable income from paddy fields, forest biomass in this area tended to be constant in the $90 \mathrm{~s}$ without outstanding forest clearing. It is, however, undergoing changes due to greater needs for wood and farmland. The topics discussed here include forest accessibility, reduction processes, and species composition. Our findings will be useful when developing management plans to promote landscape heterogeneity for biological conservation (Marin et al. 2005, Yoneda et al. 2009, Laumonier et al. 2010).

\section{MATERIALS AND METHODS}

\section{Study site}

The study site, which includes forests neighboring Sipisang village, is located in Padang Pariaman District, along the upper stream of the Batang Anai River where the hills of Barisan Mountain can be observed (refer to a map (Fig.1 in Yoneda et al. 2006)). The average monthly rainfall is estimated to be $445 \mathrm{~mm}$, the mean annual precipitation is approximately $5340 \mathrm{~mm}$, and the mean annual temperature is $23.5^{\circ} \mathrm{C}$ (Syahbuddin and Mukhtar 1996). The land-use system has been being characterized by small-scale forest activities such as selective logging and collecting tree resins (dammar) and rattan (Yoneda 2000). Major sources of incomes include products such as rice, Pithecellobium lobatum (jengkol), banana, Coffea robusta, Hevea brasiliensis (rubber), Durio zybethinus (durian), and Garcinia mangostana (mangosteen). The landscape includes sawah (irrigated rice fields) in the lowland zone, kebun (crop plants), shifting cultivation lands, and secondary and primary forests (in higher areas). The region is currently facing distinct changes due to greater needs for wood and farmland. This research represents a continuation of observations that have been conducted in this area under different contexts

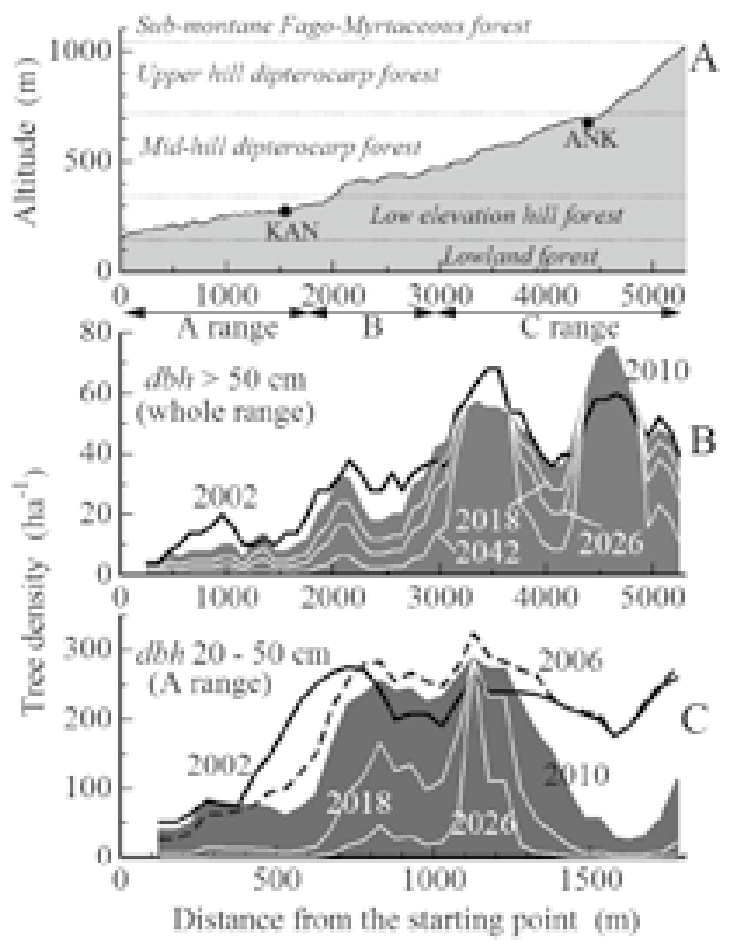

Fig. 1. A: Altitude changes of a belt transect along the distance from the starting point. Forest zonation follows Nishimura et al. (2006) and Laumonier (1997). B and C: Horizontal distribution patterns of tree density over the last 8 years from 2002 . Figures in these diagrams are calendar years. White curves show simulated patterns based on Eq. (2).

since 1994 (Yoneda et al. 2006).

Two 10-m-wide belt transects and two permanent plots were used, including a "Main Range (A-range = 0-1900 m)" and "Extended Range (B-range (1900-3000 m) + C-range (3000-5514 m))" as belt-transects, as well as the Kandis Plot (KAN) and Angkang Plot (ANK) (Fig. 1A; "Main Range" and "Extended Range" correspond to symbols of ALT and Extended ALT of Table 1 in Yoneda et al. (2006)). Main Range and KAN are located in a rural forest zone, whereas Extended Range and ANK are located at a distance from the nearest village, Sipisang. The secondary forest has suffered both from selective logging and clear cutting. These human impacts could be observed throughout the whole range, while ANK is an old growth forest with few traces of logging. Monitoring of the tree dynamics has been conducted at these sites since 1994. General features of the study sites are shown in Table 1. 
Table 1. Physical features and target trees in two belt transects and two permanent plots. *Area in ha

\begin{tabular}{lcccc}
\hline & Main range (A range) & $\begin{array}{c}\text { Extended range } \\
(\mathrm{B}+\mathrm{C} \text { ranges })\end{array}$ & Kandis plot (KAN) & Angkang plot (ANK) \\
\hline Length $(\mathrm{m})$ & 2013 & 3567 & $0.75^{*}$ & $1.00^{*}$ \\
Altitude $(\mathrm{m})$ & $150-325$ & $325-1190$ & $245-275$ & $600-650$ \\
Target trees & $d b h \geq 20 \mathrm{~cm}$ & $d b h \geq 50 \mathrm{~cm}$ & $d b h \geq 8$ & $d b h \geq 8$ \\
Period & $1994-2010$ & $2001-2010$ & $1995-2006$ & $2001-2010$ \\
& & & $8(1995,1996,1998,1999$, & $4(2001,2002,2006,2010)$ \\
\hline
\end{tabular}

\section{Tree census and definitions}

Tree censuses have been conducted at these study sites since 1994. The latest took place in 2010 but excluded KAN, which underwent clear-cut logging between 2006 and 2010 (Table 1). The stem diameter at breast height, $d b h$, was measured during each census and any new trees (recruited trees) were registered. Parameters such as position, distance, and altitude were recorded for each individual tree (Yoneda et al. 2006).

We assessed the horizontal distribution patterns of tree density with moving average values for a coverage of $50-\mathrm{m}$ length for the 20-50-cm $d b h$ and 100-m length for trees over $50 \mathrm{~cm}$ in $d b h$ with $25-\mathrm{m}$ and $50-\mathrm{m}$ intervals, respectively. Mortality $(M)$ of a tree was calculated by $M$ $=\ln \left(X_{1} / X_{2}\right) /$ period, where $X_{1}$ and $X_{2}$ are the initial and final values of tree number and basal area, respectively. The stem hardness of canopy trees in the two permanent plots was observed using the nail method, and had dimension of [ $\left.\mathrm{kg} \mathrm{f} \mathrm{cm}^{-1}\right]$ (Yoneda, 1977, Yoneda et al. 2006).

Yoneda et al. (2009) defined tree guild basing on growth traits of a species with parameters such as stem hardness, an intrinsic growth rate and attainable maximum tree size. Here we define stem hardness to be an indicator of species group composition through deforestation process. Soft and hard wood groups are made based on species.

We assessed rates of deforestation in terms of tree density and basal area across different $d b h$ classes and different periods by using following equation:

$$
M=-a X+b,
$$

where parameters $a$ and $b$ are constant, and $M$ and $X$ are mortality and the average value of tree density and basal area during each period, respectively. Eq. (1) is a socalled $S-N$ relation of a logistic equation with a negative relative growth rate and a potential mortality $=b$
(Shinozaki 1961). A parameter of $b$ is the ideal maximum mortality at $X \doteqdot 0$, and $b / a$, ratio show the $X$ value at $M=0$, the ideal maximum dimension of forest structure under stable conditions. We call them as the potential mortality and the potential tree number in case of $X$ =tree number, respectively. They correspond to the intrinsic growth rate and the maximum size of a logistic growth equation. When we integrate Eq. (1) with respect to time $(t)$, tree density at a given time, $N(t)$, could be shown by the following equation:

$$
N(t)=b / a /\{1+c \times \exp (b t)\},
$$
where parameter $c$ is an integral constant, $c=b /\left(a N_{0}\right)-1$. $N_{0}$ is tree density at $t=0$.

\section{RESULTS}

\section{Spatial expansion of deforestation}

Figure 1 shows obvious variations in tree densities over the past 8 years (2002-2010), even though the dimensional structure had been approaching dynamic equilibrium during the previous 8 years (1994-2002; Table 2; Yoneda et al. 2006). From 2002 to 2006, a large reduction in tree density for trees $20-50-\mathrm{cm} d b h$ was observed within the closer zone of A-range, i.e., 400-700 $\mathrm{m}$ from human habitats, whereas no such decrease was observed farther away. Conversely, from 2006 to 2010, a drastic reduction in tree density was recorded within the distant zone of A-range, i.e., 1300-1900 $\mathrm{m}$ in distance (Fig. 1C). This reduction was mainly the result of clearing for farmland. Within the closer zone, many trees were no longer present, and few logged stumps were found due to the slashed trees, whereas burned stumps were observed in the distant zone in 2010. Four large canopy gaps of 80$140 \mathrm{~m}$ in horizontal length were present in the A-range in 2010, whereas only two gaps were present in 2006 and one in 2002. The results of our simulations (Fig. 1C) show 
Table 2. Time trends of average basal area of a belt transect based on a unit area of $1000 \mathrm{~m}^{2}$ for two $d b h$ classes, $20-50 \mathrm{~cm}$ and $>20 \mathrm{~cm}$, and $2500 \mathrm{~m}^{2}$ for larger trees $>50 \mathrm{~cm}$ in $d b h$. Values for years with asterisks were estimated from Eq. (2) using the most recent observed basal area. Abbreviations: avg, std, and $B A$ represent average value, standard deviation, and basal area, respectively.

\begin{tabular}{|c|c|c|c|c|c|c|c|c|}
\hline \multirow[b]{2}{*}{ time } & \multicolumn{4}{|c|}{ trees $20-50-\mathrm{cm} d b h$ in A-range } & \multicolumn{4}{|c|}{ trees above $20-\mathrm{cm} d b h$ in A-range } \\
\hline & $\operatorname{avg} B A \quad\left(\mathrm{~m}^{2} \mathrm{ha}^{-1}\right)$ & $\operatorname{std} B A\left(\mathrm{~m}^{2} \mathrm{ha}^{-1}\right)$ & skewness & kurtosis & $\operatorname{avg} B A \quad\left(\mathrm{~m}^{2} \mathrm{ha}^{-1}\right)$ & std $B A\left(\mathrm{~m}^{2} \mathrm{ha}^{-1}\right)$ & skewness & kurtosis \\
\hline 1994 & 12.2 & 1.06 & 0.17 & -0.47 & 17.1 & 1.80 & 1.01 & 1.46 \\
\hline 2002 & 13.6 & 1.05 & -0.48 & -0.47 & 18.3 & 1.69 & 0.44 & 0.71 \\
\hline 2010 & 9.0 & 1.03 & 0.32 & -0.97 & 12.6 & 1.69 & 1.38 & 3.18 \\
\hline $2014^{*}$ & 8.2 & 1.11 & 0.96 & 0.22 & 10.5 & 1.62 & 2.21 & 5.92 \\
\hline \multirow[t]{2}{*}{$2018^{*}$} & 3.9 & 1.03 & 2.54 & 5.87 & 6.2 & 1.48 & 3.51 & 14.52 \\
\hline & \multicolumn{4}{|c|}{ trees above $50-\mathrm{cm} d b h$ in A-range } & \multicolumn{4}{|c|}{ trees above $50-\mathrm{cm} d b h$ in whole range } \\
\hline time & $\operatorname{avg} B A \quad\left(\mathrm{~m}^{2} \mathrm{ha}^{-1}\right)$ & std $B A\left(\mathrm{~m}^{2} \mathrm{ha}^{-1}\right)$ & skewness & kurtosis & $\operatorname{avg} B A \quad\left(\mathrm{~m}^{2} \mathrm{ha}^{-1}\right)$ & std $B A\left(\mathrm{~m}^{2} \mathrm{ha}^{-1}\right)$ & skewness & kurtosis \\
\hline 2002 & 5.25 & 0.92 & 0.88 & 0.09 & 12.7 & 1.18 & 0.44 & -0.49 \\
\hline 2006 & 4.54 & 0.81 & 1.31 & 1.89 & - & - & - & - \\
\hline 2010 & 4.22 & 0.86 & 1.39 & 0.80 & 12.0 & 1.29 & 0.66 & 0.07 \\
\hline $2014^{*}$ & 3.53 & 0.77 & 1.48 & 1.00 & 11.3 & 1.32 & 0.70 & -0.38 \\
\hline $2018^{*}$ & 2.92 & 0.68 & 1.54 & 1.19 & 10.6 & 1.34 & 0.92 & 0.27 \\
\hline
\end{tabular}

that these patterns would induce high retrogress of a secondary forest below $500 \mathrm{~m}$ in altitude in A-range by 2026

Trees larger than $50-\mathrm{cm} d b h$ in the A-range also experienced drastic reductions over the last 8 years, and they followed the same spatial patterns as smaller trees. Overall, the greatest loss occurred within the 1900-3000-m distance from humans (B-range), and the C-range (greater than $3000 \mathrm{~m}$ ) also showed large variations. The simulated horizontal distribution patterns of these canopy trees in the whole range suggest their extinction in the A-range and disappearing of floristic features below $1050 \mathrm{~m}$ in altitude by 2042 (Fig.1B)

Figure 2 suggests that the reductions in the A- and B-range are mainly caused by logging, whereas the variations within the C-range are the result of the high dynamics of big trees through natural death (around 3500 $\mathrm{m}$ distance) and new establishment (around $4000 \mathrm{~m}$ distance). A total of $40 \%$ of the logged trees in the B and C ranges were Dipterocarpaceae. Stable tree density was observed within the 800-1300-m zone for trees $20-50 \mathrm{~cm}$ in $d b h$ and at around $2000 \mathrm{~m}$ in distance for big trees because of difficulties of forest clearing and logging. The topography in these areas consisted of a steep ridge and a site surrounded by steep slopes and cliffs, respectively.

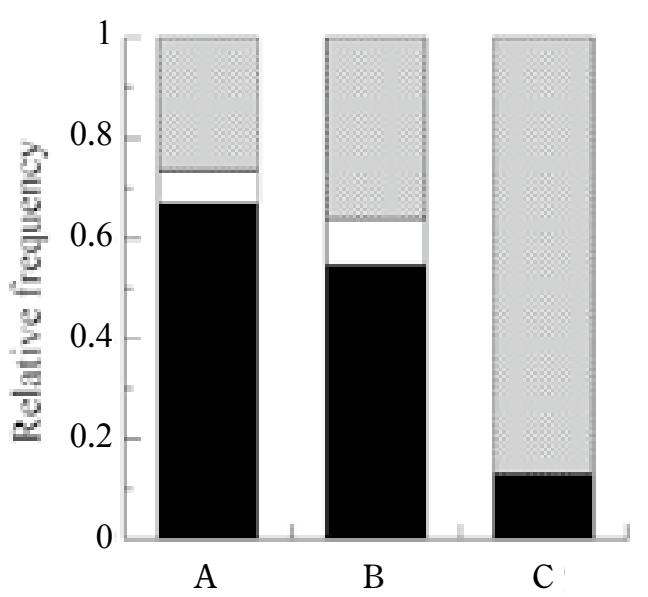

Fig. 2. Factors associated with the death of big trees $>50-\mathrm{cm}$ $d b h$ over the last 8 years at three ranges of a belt transect. The symbols $\mathrm{A}, \mathrm{B}$, and $\mathrm{C}$ are ranges of 0 $1900 \mathrm{~m}, 1900-3000 \mathrm{~m}$ and $3000-5514 \mathrm{~m}$ from the starting point, respectively. Closed, open, and hatched bars are logging, missing, and natural death, respectively. Logging is defined as stumps showing evidence of cutting; natural death refers to fallen and standing dead trees.

\section{Yearly changes in stand structure}

We examined the local stand structure in the A-range as an indicator of stem density of large trees greater than 50$\mathrm{cm} d b h$ based on monitoring data since 1994 . The density 


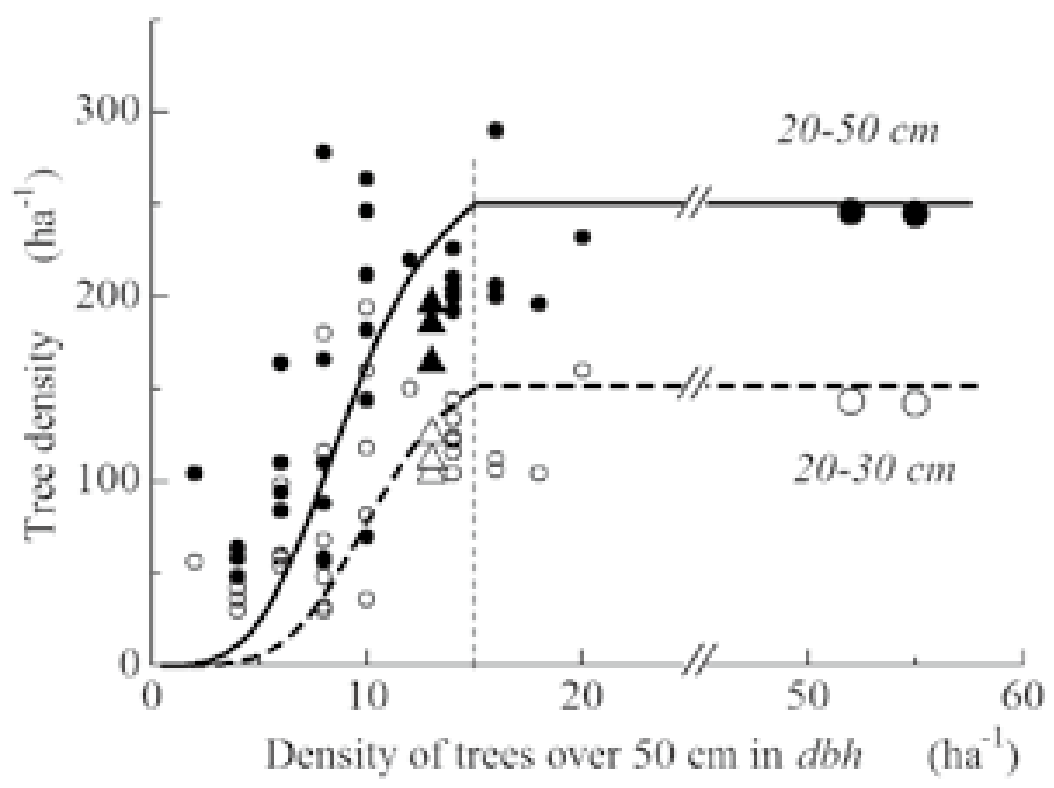

Fig. 3. Reduction process of a forest structure as an indicator of density of canopy trees $>50 \mathrm{~cm}$ in $d b h$. Small closed $(20-50 \mathrm{~cm})$ and open $(20-30 \mathrm{~cm})$ circles are observed values in the A-range from the last four censuses. Closed and open triangles were observed at KAN over the last three censuses. Large closed $(20-50 \mathrm{~cm})$ and open $(20-30 \mathrm{~cm})$ circles represent ANK in the C-range from the last two censuses. The two sigmoid curves in a diagram show the estimated relationships from Eq. (2) under conditions in which the initial density was 15,250 , and $150 \mathrm{ha}^{-1}$ for $>50-\mathrm{cm}, 20-50-\mathrm{cm}$, and 20-30-cm $d b h$ trees, respectively.

of trees $20-50 \mathrm{~cm}$ in $d b h$ was nearly equal to that of an old-growth forest stand, ANK, which showed, at density of the big trees, more than 15 trees ha ${ }^{-1}$ (Fig. 3). The trees densities tended to decrease with decrease of large trees $>50-\mathrm{cm}$ at fewer densities than 15 trees $\mathrm{ha}^{-1}$. The stand structure of KAN, an A-range plot that is regenerating from selective logging, almost satisfied this positive relationship.

The chronological changes in the frequency distribution patterns of basal area showed variations in skewness and kurtosis (Table 2). Within the A-range, an approximately symmetric distribution (skewness) was observed for the 20-50-cm $d b h$ class in $1994(0.17)$ and $2002(-0.48)$. Values of kurtosis did not vary $(-0.47)$ and showed a platykurtic trend. In 2010, greater right skewness (0.32) and a wider spread of values around the normal distribution (-0.97) were observed. This was mainly due to the reduction in basal areas of $4.57 \mathrm{~m}^{2} \mathrm{ha}^{-1}$ in 2010 as opposed to the gain of $1.39 \mathrm{~m}^{2} \mathrm{ha}^{-1}$ observed in 2002. A relatively similar trend could be observed for trees $>20 \mathrm{~cm}$ in $d b h$ in 1994 and 2002. However, the distribution is highly skewed to the right in 2010 (1.38), showing a leptokurtic trend (3.18). This large variance was caused by sympatric reduction of large and small trees (Fig. 3). The basal area loss in the A-range was estimated to be $5.68 \mathrm{~m}^{2} \mathrm{ha}^{-1}$ in 2010 compared with a gain of $1.17 \mathrm{~m}^{2} \mathrm{ha}^{-1}$ in 2002 .

In 2010, the highly dispersed distribution patterns of large trees $>50 \mathrm{~cm}$ in $d b h$ in the A-range caused a higher right skewness and leptokurtic trend compared with those of smaller trees in the same range as well as the same-sized large trees across the whole range. Constancy in the dynamics of large trees in the C-range produced a moderately right-skewed distribution (0.66) with a mesokurtic trend (0.07) across the whole range.

\section{Yearly changes in loss rates}

With Eq. (1), when we assessed rates of deforestation in terms of tree density and basal area across different $d b h$ classes and different periods, mortality $(M)$ tended to exhibit a negative relationship with both parameters $(X)$. This linear equation shows that rates of deforestation are accelerated with a decrease in the two parameters. A higher coefficient of determination could be regressed in mortality of trees excluding recruited trees especially 
(Table 3). An evaluation of mortality during each period with the parameter $b$ clearly showed a recent increase in the A-range. Over the last 4 years (2006-2010), this value exceeded by 3 to 4 times that in 1994-2002 for trees in the $20-50-\mathrm{cm} d b h$ class. The mortality including recruited trees during 2002-2010 remained high, with an average value of approximately $65 \%$ excluding recruited trees. Table 3 shows that smaller trees had higher mortality during the last 8 years both with and without recruited trees included. This was due to an increase in logging activities in areas near the village where there are few big trees.

Dimension of a forest structure could be qualified with Eq. (1). While the potential mortality of trees $>20-\mathrm{cm}$ $d b h$ clearly increased in the A-range during last 8 years, the dimension of potential tree number tended to be constant (Fig. 4).
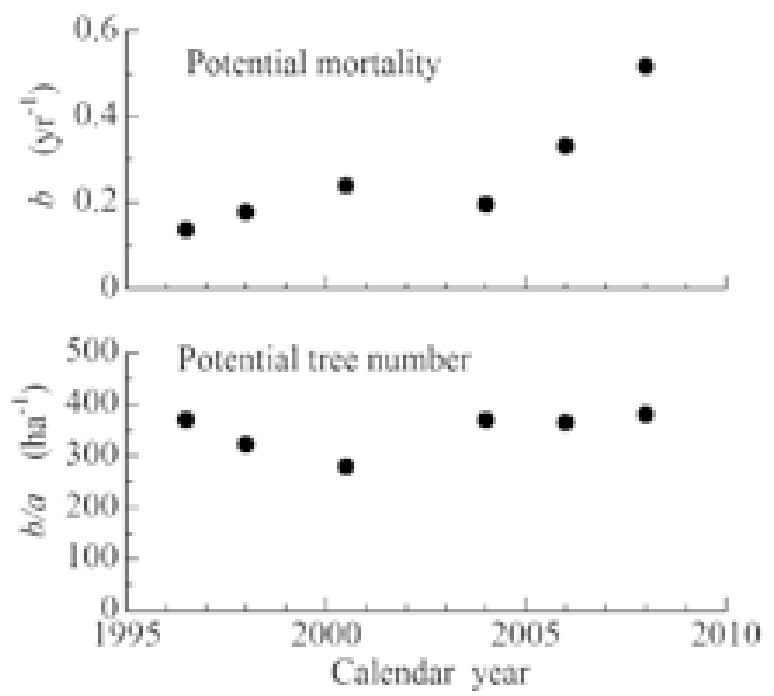

Fig. 4. Time trends of potential mortality $(b)$ and potential tree number $(b / a)$ for trees above $20 \mathrm{~cm} d b h$ in A-range under the conditions without recruited trees (Table 3).

Table 3. Two regression coefficients of Eq. (1), $a$ and $b$, from different $d b h$ classes and periods. Abbreviations: $N, B A, \mathrm{R}^{2}$, and $P$ represent tree density, basal area, a coefficient of determination, and significance level, respectively. Bold letters show parameters that are statistically significant at $P<0.05$.

\begin{tabular}{|c|c|c|c|c|c|c|c|c|c|}
\hline \multicolumn{2}{|l|}{$d b h$ class } & \multicolumn{4}{|c|}{ without recruitment } & \multicolumn{4}{|c|}{ with recruitment } \\
\hline N/BA & period & $a$ & $b$ & $\mathrm{R}^{2}$ & $P$ & $a$ & $b$ & $\mathrm{R}^{2}$ & $P$ \\
\hline \multicolumn{10}{|c|}{$d b h=20-30 \mathrm{~cm}$} \\
\hline $\mathrm{N}$ & $02-10$ & -0.00240 & 0.519 & 0.501 & 0.00 & -0.00173 & 0.298 & 0.290 & 0.00 \\
\hline BA & $02-10$ & -0.05727 & 0.551 & 0.499 & 0.00 & -0.03633 & 0.294 & 0.268 & 0.00 \\
\hline \multicolumn{10}{|c|}{$d b h=20-50 \mathrm{~cm}$} \\
\hline \multirow[t]{6}{*}{$N$} & $94-02$ & -0.00046 & 0.154 & 0.393 & 0.00 & -0.00019 & 0.020 & 0.048 & 0.20 \\
\hline & $02-10$ & -0.00110 & 0.368 & 0.204 & 0.01 & -0.00089 & 0.249 & 0.173 & 0.01 \\
\hline & $94-99$ & -0.00081 & 0.225 & 0.430 & 0.00 & -0.00057 & 0.126 & 0.199 & 0.01 \\
\hline & $99-02$ & 0.00011 & 0.021 & 0.035 & 0.28 & 0.00069 & -0.224 & 0.262 & 0.00 \\
\hline & $02-06$ & -0.00058 & 0.205 & 0.303 & 0.00 & -0.00059 & 0.139 & 0.275 & 0.00 \\
\hline & $06-10$ & -0.00145 & 0.532 & 0.158 & 0.02 & -0.00092 & 0.343 & 0.068 & 0.13 \\
\hline \multirow[t]{6}{*}{$B A$} & $94-02$ & -0.00670 & 0.135 & 0.282 & 0.00 & -0.00323 & 0.036 & 0.072 & 0.11 \\
\hline & $02-10$ & -0.01651 & 0.362 & 0.148 & 0.02 & -0.01126 & 0.234 & 0.109 & 0.05 \\
\hline & $94-99$ & -0.01120 & 0.209 & 0.322 & 0.00 & -0.00889 & 0.148 & 0.226 & 0.00 \\
\hline & $99-02$ & 0.00343 & -0.050 & 0.124 & 0.04 & 0.01004 & -0.220 & 0.371 & 0.00 \\
\hline & $02-06$ & -0.00001 & 0.130 & 0.159 & 0.02 & 0.00000 & 0.084 & 0.119 & 0.04 \\
\hline & $06-10$ & -0.02373 & 0.556 & 0.138 & 0.03 & -0.01410 & 0.367 & 0.061 & 0.15 \\
\hline \multicolumn{10}{|l|}{$d b h \geq 20 \mathrm{~cm}$} \\
\hline \multirow[t]{6}{*}{$N$} & 94-02 & -0.00055 & 0.178 & 0.420 & 0.00 & -0.00040 & 0.075 & 0.153 & 0.02 \\
\hline & $02-10$ & -0.00091 & 0.332 & 0.185 & 0.01 & -0.00076 & 0.233 & 0.143 & 0.03 \\
\hline & $94-99$ & -0.00037 & 0.137 & 0.261 & 0.00 & -0.00022 & 0.060 & 0.104 & 0.05 \\
\hline & $99-02$ & -0.00086 & 0.240 & 0.192 & 0.01 & -0.00064 & 0.078 & 0.070 & 0.11 \\
\hline & $02-06$ & -0.00053 & 0.196 & 0.292 & 0.00 & -0.00052 & 0.132 & 0.269 & 0.00 \\
\hline & $06-10$ & -0.00136 & 0.518 & 0.151 & 0.02 & -0.00083 & 0.329 & 0.062 & 0.15 \\
\hline \multirow[t]{6}{*}{$B A$} & $94-02$ & -0.00556 & 0.155 & 0.199 & 0.01 & -0.00415 & 0.091 & 0.102 & 0.05 \\
\hline & $02-10$ & -0.00713 & 0.257 & 0.094 & 0.07 & -0.00458 & 0.169 & 0.050 & 0.20 \\
\hline & $94-99$ & -0.00210 & 0.076 & 0.085 & 0.08 & -0.00103 & 0.034 & 0.035 & 0.27 \\
\hline & $99-02$ & -0.01112 & 0.270 & 0.120 & 0.04 & -0.00917 & 0.177 & 0.074 & 0.10 \\
\hline & $02-06$ & -0.00258 & 0.088 & 0.101 & 0.06 & -0.00190 & 0.046 & 0.058 & 0.16 \\
\hline & $06-10$ & -0.01400 & 0.481 & 0.109 & 0.05 & -0.00808 & 0.320 & 0.046 & 0.21 \\
\hline \multicolumn{10}{|l|}{$d b h \geq 50 \mathrm{~cm}$} \\
\hline$N$ & $02-10$ & -0.00277 & 0.187 & 0.151 & 0.01 & -0.00140 & 0.075 & 0.179 & 0.01 \\
\hline$B A$ & $02-10$ & -0.00839 & 0.187 & 0.157 & 0.01 & -0.00321 & 0.065 & 0.121 & 0.02 \\
\hline
\end{tabular}




\section{Simulated spatio-temporal changes of tree density}

Basing on Eq. (2), Fig. 5 shows simulated future time trends of tree density (A) and ratios of number of trees remaining from the initial conditions to the total trees including newcomers (B) with parameters during the period 2002-2010. Compared to the pattern with parameters during first former 8 years (1994-2002), loss rates are conspicuously high. Density changes increase with a decrease in $d b h$ class. Even when there is relative constancy during the first decade, $d b h$ classes of 20-30, $30-50$, and $>20-\mathrm{cm} d b h$ are predicted to show drastic decreases in population sizes within 50 years in the A-range. However, a relative constancy is observed in the trees over $50-\mathrm{cm} d b h$. This is mainly due to their low mortalities and large variances in the C-range.

Figure 1 shows simulated spatio-temporal changes of tree density in this study site with parameters of present local tree density and average mortality during
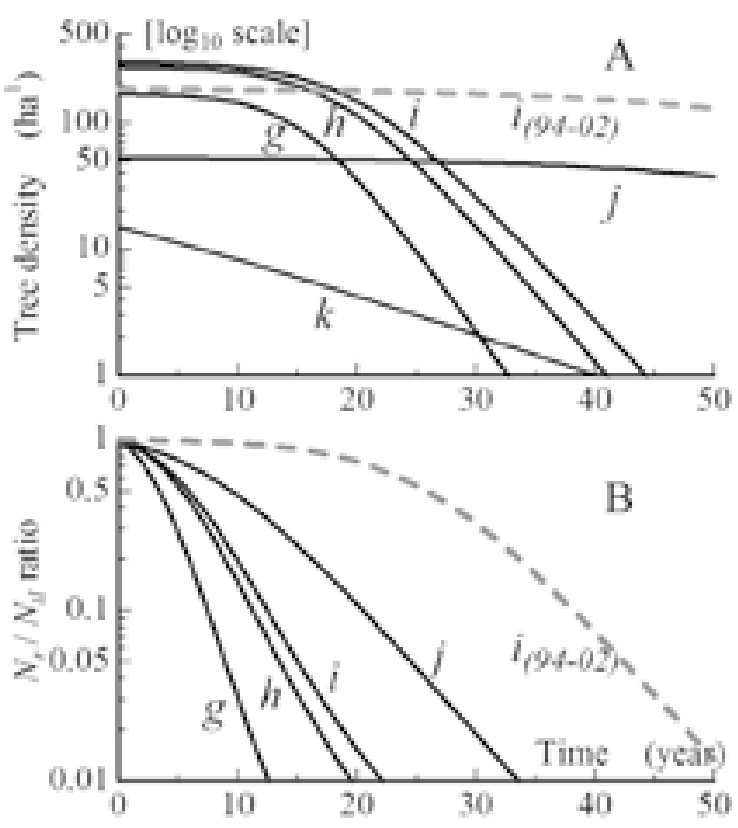

Fig. 5. Estimated time trends of tree density (A) and $N_{\mathrm{r}} / N_{\mathrm{tl}}$ ratio (B) by Eq. (2) with parameters during the period of 2002-2010. $N_{\mathrm{r}}$ and $N_{\mathrm{tl}}$ represent the number of trees remaining from the initial conditions and total trees including newcomers, respectively. The symbols $g, h$, and $i$ are $d b h$ classes of $20-30 \mathrm{~cm}, 30-50 \mathrm{~cm}$, and above $20 \mathrm{~cm}$ in the A-range $(0-1900 \mathrm{~m})$, and $j$ represents the class above $50 \mathrm{~cm}$ over the whole range. Broken curves with a symbol of $i(94-02)$ are patterns of $i$ from parameters in 1994-2002. Their initial tree densities are set at $0.99 \times$ the potential tree density. $k$ represents the class above $50 \mathrm{~cm} d b h$ with the initial tree density of $15 \mathrm{ha}^{-1}$. the last 8 years. This could show that most trees would disappear from the A-range by 2026 (Fig. 1B and C), and large trees within the B-range would undergo a decrease in density, resulting in density comparable to that of the A-range in 2002. A large reduction in the C-range may be overestimated due to a priori conditions influencing the initial tree density regardless of the local conditions.

\section{Stem growth rates of KAN and ANK}

Based on long-term observations (1995-2006 for KAN, 2001-2010 for ANK), ANCOVA analysis by using $d b h$ as co-variance could show that trees $>10-\mathrm{cm} d b h$ within KAN showed significantly higher relative growth rates compared with an old-growth forest within ANK in the C-range $\left(F_{1,961}=254.8, P<0.001\right.$, SPSS.Ver.15). The rates had significant negative correlation with $d b h(P<0.01)$, and the values of canopy trees $>30-\mathrm{cm} d b h$ at Kandis was $0.018 \mathrm{~cm} \mathrm{~cm}^{-1} \mathrm{y}^{-1}$ against $0.0071 \mathrm{~cm} \mathrm{~cm}^{-1} \mathrm{y}^{-1}$ at Angkang.

\section{DISCUSSION}

\section{Changes in dimensional structure}

The dimensional structure in A-range was characterized by an increase in potential mortality and constancy in potential tree number (Fig. 4). An increase in need of farmlands could be a major factor in this increase, and the constancy of a $b / a$ ratio likely reflect intact forest stands that did not undergo recent logging due to inaccessibility. The chronological changes of these trends in this study site generally indicate that the recent reductions in forested area are likely due to rapid expansion over a wide area, which has resulted in fragmented stands.

Figure 5A shows that persistent disturbance leads to a rapid loss of tree density within a few decades depending on tree size. High mortality during the last 8 years, 2002-2010, could be confirmed through distinct differences from the patterns $\left(i_{(94-02)}\right.$ in Fig.5) with parameters during the former 8 years, 1994-2002. Additionally, given the observed recent increase in mortality (Fig. 4), this period could be reduced.

The constancy of large canopy trees $>50-\mathrm{cm} d b h$ across the whole range is related to their low mortalities and large variances in the C-range. The density dependency of Eq. (2) shows that the trend follows a steeper slope for the initial density $\left(N_{0}\right)$ of $15 \mathrm{ha}^{-1}$ (Fig. 5A, pattern $k$ ). This could induce dynamic changes in dimensional structure of a rural forest (Fig. 3). An estimation of temporal changes in horizontal distribution 
patterns of tree density with the present local value for $N_{0}$ shows that vegetational reduction progresses more rapidly than the $k$ pattern (Fig. 1B). The reduction process within the secondary forest would result in a decreased average basal area as well as an increase in the skweness and kurtosis in the tree distribution patterns within the local basal area (Table 2).

\section{Changes in species composition}

Figure 5B highlights the high mortality of remaining trees, which should be replaced by recruited trees within the next 35 years. Smaller individuals show faster changes. Therefore, over the next 20 years, recruited trees should account for $99 \%$ of trees $<50-\mathrm{cm} d b h$ in the A-range (curves of $g$ and $h$ in Fig. 5B), while the proportion would be only $25 \%$ for the simulation with parameters in 1994-2002 ( $i_{(94-02)}$ in Fig.5). High competition among these recruited trees would be expected. When we examined the relative growth rates of 289 trees $>10$ $\mathrm{cm} d b h$ within KAN based on a long-term monitoring data from the past 11 years (1995-2006), ANCOVA analysis by using stem hardness as co-variance could show that relative growth rates were not signigicantly different among three $d b h$ classes being 10-20 cm, 20-30 cm and above $30 \mathrm{~cm}\left(F_{2,285}=2.369, P=0.095\right.$; SPSS.Ver.15). However higher relative growth rate was observed in trees with lower co-variance, i.e., stem hardness $\left(F_{1,285}=\right.$ 13.99, $P<0.001$; SPSS.Ver.15). This analysis based on data of individuals because of limitation of tree number per species, however suggests that guilds of species with softer wood could predominate during this regeneration process (Turner 2001, Laurence et al. 2004, Yoneda et al. 2009). Most of the remaining large canopy trees $>50 \mathrm{~cm}$ in $d b h$ would also dissapear from the entire range over the next 35 years based on their high mortality (18.7\% per year), although the total number of trees lost during this period was only $9 \%$ due to the high recruitment ratio. Canopy trees of KAN showed significantly higher relative growth rates than one at ANK in the C-range. This indicates rapid replacement of canopy trees, thus shifting the community from a primary forest to a secondary forest throughout the whole range, although differences in the original vegetation along an altitudinal gradient should also be considered (Fig. 1).

\section{Impacts on floristic structure in a hill dipterocarp forest zone}

We observed three types of hill depterocarp forest on the west-facing slopes of the Barisan Mountains in the coastal region of Padang Plain (Fig. 1A). These were distributed at $150-1050 \mathrm{~m}$ in altitude as a lower-hill depterocarp forest (LHDF) (Laumonier 1997), a mid-hill dipterocarp forest (MHDF), and an upper-hill dipterocarp forest (UHDF) (Nishimura et al. 2006). Their floristic features were characterised by high dominance of Fagaceae and Myrtaceae, low dominance of Dipterocarpaceae, and high species diversity of Fagaceae (Nishimura et al. 2006, Fujii et al. 2006). In the mid-1990s within the Padang Pariaman District (Sipisang), located on the northern edge of the plain, the forest still exhibited these original features of a rural and selectively logged forest (Yoneda et al. 2006). Conversely, the piedmont district of Mt. Gadut near Padang City, Ulu Gadut area, had already lost LHDF and exhibited scatterred and isolated MHDF due to human disturbances. Following the Asian economic crisis in 1997, human impacts were acceralated through clearing and logging in this region. Our field observations by 2011 have revealed that most of the old-growth hill dipterocarp forest had disappeared from the Ulu Gadut area. The results of this study basing on the field observation during the last 16 years suggest that a similar rapid reduction will occur within the hill dipterocarp forest in this area because of a demand for a higher income under economic autonomy policy in Indonesia. In this case, the secondary forest at the LHDF zone would disappear, and the lower-altitude portion of the MHDF (below $500 \mathrm{~m}$ in altitude) would largely retrogress within the next 16 years (Fig. 1B:simulation in 2026) and could disappear within the next 32 years (16 years ahead from 2026, simulation in 2042). The upper portion of the MHDF and UHDF would be dominated by secondary species during this period. The hill dipterocarp forest community would be vulnerable to human disturbances due to habitat isolation by altitudinal and topographical barriers. Retrogression of the remnants would destroy the floristic structure in this region. Laumonier et al. (2010) highlighted the merits of a conservation prioritization system based on ecological and biogeographical knowledge. Our results indicate that this study area should be of high priority for conservation.

ACKNOWLEGEMENTS We express our sincere thanks to Drs. Eizi Suzuki (Kagoshima University), Sen Nishimura (Sumitomo Forestry Co.), Shinji Fujii (University of Human Envionments), Yasuhiko Kubota (Ryukyu University), and Erizal Mukhtar and Chairul of Andalas University for their valuable comments and support, as well as to many students of Japanese 
universities and Andalas University. Finally, we express our gratitute to the local people in Sipisang for their cooperation during the fieldwork. This study was partly supported by the Nippon Life Insurance Foundation in 1995 (T. Yoneda), by Grants-in-Aid (Oversea-B-12575006) from the Japanese Ministry of Education, Science, Sports and Culture during 2000-2003 (T. Yoneda), by Global Environmental Research Fund (E-051), Ministry of the Environment, Japan during 2005-2007 (E. Suzuki), and by the Japanese Society for the Promotion of Science (JSPS) through the International Training Program of Kagoshima University during 2007-2012 (E. Suzuki).

\section{REFERENCES}

ASEAN 2009. ASEAN Centre for Biodiversity: Conserving and managing biodiversity at the regional level. First ASIAHORCS Joint Symposium, 18-20 July, Nagoya, Japan.

Everham III EM, Brokaw NVL. 1996. Forest damage and recovery from catastrophic wind. The botanical review 62: 113-185.

FWI/GFW. 2002. The State of the Forest: Indonesia. Bogor, Indonesia: Forest Watch Indonesia, and Washington DC: Global Forest Watch.

Folke C., Carpenter S., Elmqvist T., Gunderson L., Holling C. S. \& Walker B. 2002. Resilience and sustainable development. Building adaptative capacity in a world of transformation. Ambio 31:437440.

Fujii S, Nishimura S, Yoneda T. 2006. Altitudinal distribution of Fagaceae in West Sumatra. Tropics 15:153-163.

Julian E. 1992. Plantation forestry in the tropics. 2nd ed. Clarendon Press Oxford, 403 pages.

Kimmins JP. 2004. Forest Ecology. A Fondation for Sustainable Forest Management and Environmental Ethics in Forestry. $3^{\text {rd }}$ ed. The University of British Columbia, 611 pages.

Kobayashi S. 2004. Landscape rehabilitation of degraded tropical forest ecosystems Case study of the CIFOR/Japan project in Indonesia and Peru. Forest Ecology and Management 201:13-22.

Lambin EF, Turner BL, Geist HJ, Agbola SB, Angelsen A, Bruce JW, Coomes OT, Dirzo R, Fischer G, Folke C, George PS, Homewood K, Imbernon J, Leemans R, Li X, Moran E, Mortimore M, Ramakrishnan PS, Richards JF, Skånes H, Steffen W, Stone GD, Svedin U, Veldkamp TA, Vogel C, Xu J. 2001. The causes of land-use and land-cover change: moving beyond the myths. Global Environmental Change 11:261-269.

Laumonier Y. 1997. The vegetation and physiography of Sumatra. Geobotany Series 22, Kluwer Academic Publishers, Dordrecht. 222 pages

Laumonier Y, Uryu U, Stuwi M, Budiman A, Setiabudi B, Hadian O. 2010. Eco-floristic sectors and deforestation threats in Sumatra: identifying new conservation area network priorities for ecosystembased land use planning. Biodiversity Conservation 19:1153-1174.

Laurance WF, Oliveira AA, Laurence SG, Condit R, Nascimento HEM, Scanchez-Thorin AC, Lovejoy JE, Andrade TE, D’Angelo A, Riberiro S, Dick CW. 2004. Pervasive alteration of tree communities in undisturbed Amazonian forests. Nature 428:171-174.

Marın GC, Nygard R, Rivas B, Oden P. 2005. Stand dynamics and basal area change in a tropical dry forest reserve in Nicaragua. Forest Ecology and Management 208:63-75.

Nishimura S, Yoneda T, Fujii S, Mukhtar E, Abe H, Kanzaki M. 2006. Factors influencing the floristic composition of a hill forest in West Sumatra. Tropics 15:165-175.

Otsuka M. 2009. Impacts of farmers' land use on natural forest conversion: A case study from West Sumatra, Indonesia. Tropics 18:155-166.

Sheil D, Burslem DFR. 2003. Disturbing hypotheses in tropical forests. Trends in Ecology and evolution 18:18-26.

Shinozaki K. 1961. Logistic theory for plant growth. Thesis of a doctor degree, Kyoto University. (in Japanese)

Syahbuddin, Mukhtar E. 1996. Ownership management and structure of plant communities at a village garden in Sipisang. Annual Report of FBRT Project, 253-257.

Top N, Mizoue N, Ito S, Kai S, Nakao T, Ty S. 2008. Effects of population density on forest structure and species richness and diversity of trees in Kampong Thom province, Cambodia. Biodiversity Conservation 18:717-738.

Turner IM. 2001. The ecology of trees in the tropical rain forest. Cambridge Tropical Biology Seres, Cambridge University Press. Cambridge. 298 pages

Vihervaara P, Rönkä M, Walls M. 2010. Trends in Ecosystem Service Research: Early Steps and Current Drivers. Journal of the Human Environment 39:314-324.

Vitousek PM, Mooney HA, Lubchenco J, Melillo JM. 1997. Human Domination of Earth's Ecosystems. 
Science 277:494-499.

Whitmore TC. 1998. An introduction to tropical rain forests. Second edition. Oxford University Press, Oxford.

William DS. 1999. The effect of economic crisis and political change on Indonesia's forest sector, 19971999. http://www.cgiar.org/cifor/research/ projects/effect-crisis.html

Yamamoto SI. 1992. The gap theory in forest dynamics. Botanical Magazine Tokyo 105:375-383.

Yoneda T. 1997. Instruction for measurement of hardness of stem wood in the field. Tropical Ecological Letters 27:17-20. (in Japananese)

Yoneda T. 2000. Vegetational structure of the Minangkabau's village, West Sumatra, Indonesia. Research Report of the Japan Center for Area Studies (JVAS) 3:49-83. (in Japanese with English summary)

Yoneda T, Mizunaga H, Nishimura S, Fujii S, Tamin R. 2006. Stand structure and dynamics of a tropical secondary forest: A rural forest in West Sumatra, Indonesia. Tropics 15: 189-199.

Yoneda T, Nishimura S, Fujii S, Mukhtar E. 2009. The tree guild composition of a hill dipterocarp forest in West Sumatra, Indonesia. Tropics 18:145-154.

Received $24^{\text {th }}$ Jan. 2012

Accepted $20^{\text {th }}$ June 2012 